\title{
Prevalence of diabetes complications and associated comorbidities in the Family Medicine setting at the Mexican Institute of Social Security
}

\author{
Oscar David Ovalle-Luna, ${ }^{1}$ Iván Abimael Jiménez-Martínez, ${ }^{2}$ Ramón Alberto Rascón-Pacheco, ${ }^{2}$ \\ Rita A. Gómez-Díaz, ${ }^{1}$ Adriana L. Valdez-González, ${ }^{1}$ Mireya Gamiochipi-Cano, ${ }^{1}$ Svetlana V. Doubova, ${ }^{3}$ \\ Adán Valladares-Salgado,, Rafael Mondragón-González,, ${ }^{4}$ Araceli Méndez-Padrón, ${ }^{4}$ \\ Martha Catalina Sánchez-Becerra, ${ }^{4}$ Miguel Cruz, ${ }^{4}$ Ana María Salinas-Martínez, ${ }^{5}$ \\ María Guadalupe Garza-Sagástegui, ${ }^{6}$ Jaime Hernández-Rubi, ${ }^{7}$ Arturo González-Hermosillo, ${ }^{7}$ \\ Héctor Raúl Vargas-Sánchez, ${ }^{8}$ Mario Reyes, ${ }^{8}$ Víctor H. Borja-Aburto ${ }^{9}$ and Niels H. Wacher ${ }^{1}$
}

${ }^{1}$ Specialty Hospital, Instituto Mexicano del Seguro Social, Centro Médico Nacional Siglo XXI, Mexico City; ${ }^{2}$ Primary Care Unit, Insituto Mexicano del Seguro Social, Mexico City; ${ }^{3}$ Epidemiological and Health Services Research Unit; ${ }^{4}$ Unit of Medical Research in Biochemistry, Specialty Hospital, Centro Médico Nacional Siglo XXI, Mexico City; ${ }^{5}$ Unit of Research in Epidemilogy and Health Services, Instituto Mexicano del Seguro Social, Delegación Regional Nuevo León, Nuevo León; ${ }^{6}$ Medical Benefits Head Office, Instituto Mexicano del Seguro Social, Delegación Regional Nuevo León, Nuevo León; 'Department of Computational Systems Engineering and Automatization, Institute of Applied Mathematical Research and Systems, Universidad Nacional Autónoma de México, Mexico City; ${ }^{8}$ Primary Care Unit, Family Medicine Division, Instituto Mexicano del Seguro Social, Mexico City; ${ }^{9}$ Medical Benefits Head Office, Instituto Mexicano del Seguro Social, Mexico City, Mexico

\begin{abstract}
Introduction: The prevalence of chronic complications and comorbidities in patients with type 2 diabetes (T2D) has increased worldwide. Objective: To compare the prevalence of complications and chronic comorbidities in patients with T2D at 36 family medicine units of five chapters of the Mexican Institute of Social Security (IMSS). Method: Complications (hypoglycemia, diabetic foot, kidney disease, retinopathy, ischemic heart disease, cerebrovascular disease and heart failure) and comorbidities (liver disease, cancer and anemia) were identified according to codes of the International Classification of Diseases, 10th Revision. Comparisons were made by chapter, age, and gender and evolution time. Results: Complications and comorbidities were more common in subjects aged $\geq 62$ years. Out of 297100 patients, $31.8 \%$ had any complication or comorbidity; microvascular complications (32\%) prevailed in the industrial North, whereas macrovascular complications (12.3\%) did in the rural East, and comorbidities (5\%) in southern Mexico City. Complications predominated in men (any complication, $30.2 \%$ ). Heart failure and comorbidities were more common in women (5.6 \% and $4.9 \%$, respectively). Conclusions: T2D complications and comorbidities showed geographic and gender differences, and were greater with older age and longer evolution time. It is urgent for strategies for the prevention of complications and comorbidities to be reinforced in patients with T2D.
\end{abstract}

KEY WORDS: Diabetes. Complications. Comorbidities. Family medicine.

\section{Introduction}

Diabetes is a chronic disease that, if not controlled, is associated with chronic complications that make it more difficult to treat the patient and cause for him/ her to be unable to carry out his/her daily activities.
Worldwide, more than 415 million people suffer from diabetes; ${ }^{1} 1.5$ million people are estimated to have died from this disease in 2012. According to projections by the World Health Organization, diabetes will be the seventh cause of death by the year 2030. A recent study reported that diabetes
Correspondence: Niels H. Wacher

E-mail: wacherniels@gmail.com
Date of reception: 27-06-2018

Date of acceptance: 04-10-2018

DOI: 10.24875/GMM.M19000230
Gac Med Mex. 2019;155:28-36

Contents available at PubMed www.gacetamedicademexico.com 
complications caused one of every three deaths from the disease. ${ }^{2}$

The profile of diabetes and its complications changed in Mexico between 2012 and 2016, according to the National Health and Nutrition Survey (ENSANUT - Encuesta Nacional de Salud y Nutrición). Adults with a previous medical diagnosis of diabetes showed a marginal increase (9.2\% vs. $9.4 \%)$; and of these, only $25 \%$ had an adequate metabolic control ( $\mathrm{HbA} 1 \mathrm{c}<7 \%$ [53 mmol/mol]). Diabetes chronic complications self-report included retinopathy, reduced vision ( $47.6 \%$ vs. $54.5 \%$ ), retinal damage ( $13.9 \%$ vs. $11.2 \%$ ), vision loss (6.6\% vs. $9.9 \%$ ), and peripheral vascular disease (ulcers [7.2\% vs. $9.1 \%$ ], amputations [2 \% vs. $5.4 \%]$ ), diabetic coma ( $2.9 \%$ vs. $1.7 \%$ ), infarction ( $2.8 \%$ vs. $3.2 \%$ ) and dialysis (1.4 \% vs. $1.2 \%)^{3-5}$

In Mexico, regional differences are observed; for example, northern Mexico City and Monterrey (Nuevo León) are actually rather industrial zones, where the population comes from middle and high socioeconomic strata and have higher levels of pollution, whereas southern Mexico City has a higher socioeconomic status and a higher level of education. On the other hand, the State of Mexico (east and west) is actually rather rural, with less pollution and lower socioeconomic status.

At the Mexican Institute of Social Security (IMSS - Instituto Mexicano del Seguro Social), many chronic complications of diabetes are initially treated by the family doctor, but as they progress, patients must be referred to specialists in hospitals.

Previous reports of diabetes complications have varied within the IMSS. Sabag Ruiz et al., from Ciudad Obregón, Sonora, reported a prevalence of neuropathy of $42.6 \%$, retinopathy of $27.5 \%$, nephropathy of $20.5 \%$, diabetic foot of $10.8 \%$, ischemic heart disease of $10 \%$ and cerebral vascular disease of $4.4 \% .{ }^{6}$ Ibarra et al. reported the prevalence of polyneuropathy in León, Guanajuato, to be $72 \%$ for women and $67 \%$ for men. ${ }^{7}$ Both reports differ from the figures reported by ENSANUT regarding the distribution of complications and suggest not-yet-explored regional differences in the prevalence of complications and specific comorbidities.

Authors from other countries have studied diabetes complications. In the United States, in a population $>40$ years of age, $4.5 \%$ were found to have arterial peripheral disease, $14.8 \%$ peripheral neuropathy and $18 \%$ lower limb disease. ${ }^{8}$ Alonso Morán et al. reported the prevalence of several complications in Spain, including kidney failure (8.4\%), stroke $(6.9 \%)$, heart failure $(4.3 \%)$, peripheral neuropathy $(1.3 \%)$ and retinopathy $(7.2 \%) .{ }^{9}$ Giorda et al. noted that the incidence of stroke in Italy in people with diabetes showed a rate per 1000 person-years of 5.5 in men and 6.3 in women, and that when there was previously known cardiovascular disease, the incidence was 13.7 in men and 10.8 in women. ${ }^{10}$ Ziegler et al. reported that the prevalence of polyneuropathy in Germans with diabetes was $28 \% .{ }^{11}$ Wong et al., in a meta-analysis, reported that the incidence of proliferative diabetic retinopathy and vision loss was $11 \%$ and $7.2 \%$, respectively. ${ }^{12}$ In 2007, Wong et al. analyzed retinopathy in Australia and reported an accumulated incidence of $10.1 \%$ and a prevalence of $27.2 \% .^{13}$

ENSANUT showed data obtained by self-report, which is often not reliable. Other studies are limited by the nature of the patients and the sample size. This study shows the prevalence of chronic complications, just as diagnosed by family doctors. The purpose of this work is to report and compare the prevalence of complications and certain comorbidities of diabetes in 36 family medicine units belonging to five IMSS delegations in Mexico City, the State of Mexico and the State of Nuevo León. In all cases, diabetes complications and certain comorbidities are estimated and compared by geographical region.

\section{Method}

From a central repository, all the medical records of patients who attended 36 family medicine units and that registered the E11 to E14 codes of the International Classification of Diseases Tenth Revision (ICD-10) were extracted in Mexico City north and south, State of Mexico east and west and Nuevo León delegations. In these delegations, 4,148,838 people are served $(9.38 \%$ of the entire population attended to by the IMSS in family medicine units). The Ethics Committee approved the protocol with the number IRB 2014-785-049.

Review of electronic records: Data analysis for this study was carried out with the $\mathrm{SAS}^{\circledR}$ software (SAS Institute Inc., Cary, NC, USA). Extracted data include age, gender, disease duration and diagnoses of complications and comorbidities (according to their ICD-10 codes) as follows: hypoglycemia, microvascular complications, retinopathy or macular edema, nephropathy and diabetic foot. Macrovascular complications included ischemic heart disease, stroke/cerebrovascular disease and heart failure. Also of interest were liver cirrhosis, anemia or hemoglobinopathies and 
Table 1. Diabetes complications and comorbidities by IMSS delegation

\begin{tabular}{|c|c|c|c|c|c|c|c|c|c|c|c|c|c|c|}
\hline \multirow[t]{2}{*}{ Complication } & \multicolumn{2}{|c|}{$\begin{array}{l}\text { Mexico City } \\
\text { North }\end{array}$} & \multicolumn{2}{|c|}{$\begin{array}{l}\text { Mexico City } \\
\text { South }\end{array}$} & \multicolumn{2}{|c|}{ Mexico East } & \multicolumn{2}{|c|}{$\begin{array}{c}\text { Mexico } \\
\text { West }\end{array}$} & \multicolumn{2}{|c|}{ Nuevo León } & \multicolumn{2}{|c|}{ Total } & \multirow[t]{2}{*}{$\chi^{2}$} & \multirow[t]{2}{*}{$p$} \\
\hline & $\mathbf{n}$ & $\%$ & $\mathrm{n}$ & $\%$ & $\mathrm{n}$ & $\%$ & $\mathbf{n}$ & $\%$ & $\mathbf{n}$ & $\%$ & $\mathrm{n}$ & $\%$ & & \\
\hline Hypoglycemia & 263 & 0.3 & 540 & 0.4 & 112 & 0.4 & 270 & 1.4 & 217 & 0.3 & 1402 & 0.4 & 429.28 & $<0.001$ \\
\hline Diabetic foot & 17596 & 24.4 & 19208 & 15.0 & 3438 & 15.0 & 1890 & 10.3 & 8503 & 15.0 & 50635 & 17.0 & $4,714.74$ & $<0.001$ \\
\hline Chronic kidney disease & 5563 & 7.7 & 9221 & 7.2 & 1741 & 7.6 & 1520 & 8.3 & 3560 & 6.3 & 21605 & 7.2 & 144.41 & $<0.001$ \\
\hline Retinopathy & 3264 & 4.5 & 6060 & 4.7 & 1278 & 5.5 & 1344 & 7.3 & 1169 & 2.0 & 13115 & 4.4 & $1,224.46$ & $<0.001$ \\
\hline Ischemic heart disease & 218 & 0.3 & 663 & 0.5 & 33 & 0.1 & 74 & 0.4 & 109 & 0.1 & 1097 & 0.3 & 166.62 & $<0.001$ \\
\hline Cerebrovascular disease & 667 & 0.9 & 1235 & 0.9 & 157 & 0.6 & 194 & 1.0 & 597 & 1.0 & 2850 & 0.9 & 26.87 & $<0.001$ \\
\hline Heart failure & 3739 & 5.2 & 6797 & 5.3 & 2694 & 11.7 & 1012 & 5.5 & 1786 & 3.1 & 16028 & 5.3 & 2374.57 & $<0.001$ \\
\hline Chronic liver disease & 363 & 0.5 & 667 & 0.5 & 85 & 0.3 & 108 & 0.5 & 315 & 0.5 & 1538 & 0.5 & 13.63 & 0.009 \\
\hline Neoplasm & 1667 & 2.3 & 2856 & 2.2 & 497 & 2.1 & 341 & 1.8 & 1095 & 1.9 & 6456 & 2.1 & 32.24 & $<0.001$ \\
\hline Anemia & 1253 & 1.7 & 3170 & 2.4 & 409 & 1.7 & 269 & 1.4 & 1085 & 1.9 & 6186 & 2.0 & 189.52 & $<0.001$ \\
\hline Any microvascular & 23015 & 32.0 & 30722 & 24.0 & 5605 & 24.4 & 4044 & 22.2 & 12303 & 21.7 & 75689 & 25.4 & 3039.36 & $<0.001$ \\
\hline Any macrovascular & 4458 & 6.2 & 8300 & 6.5 & 2833 & 12.3 & 1219 & 6.7 & 2429 & 4.3 & 19239 & 6.4 & 1761.37 & $<0.001$ \\
\hline Any complication & 25107 & 34.9 & 35980 & 28.1 & 7418 & 32.3 & 4795 & 26.3 & 13802 & 24.4 & 87102 & 29.3 & 2697.07 & $<0.001$ \\
\hline Any comorbidity & 3161 & 4.4 & 6451 & 5.05 & 959 & 4.1 & 697 & 3.8 & 2410 & 4.2 & 13678 & 4.6 & 112.59 & $<0.001$ \\
\hline Any complication or comorbidity & 26583 & 36.9 & 39529 & 30.9 & 7930 & 34.6 & 5177 & 28.4 & 15286 & 27.0 & 94505 & 31.8 & 2376.20 & $<0.001$ \\
\hline Total subjects & 71893 & & 127646 & & 22905 & & 18206 & & 56540 & & 297100 & & & \\
\hline
\end{tabular}

cancer within the last five years. Each complication or comorbidity was coded as 0 , absent, or 1 , present.

For the statistical analysis, we estimated the prevalence rates of each complication and comorbidity. Comparisons were made by age, gender, delegation and disease duration (when the information was available) by means of the $\chi^{2}$ test. Associations were estimated with the odds ratio (OR) and its corresponding $95 \%$ confidence interval $(\mathrm{Cl})$.

Logistic regression analyses were performed including age, gender, delegation and diabetes duration. P-values $<0.05$ were considered significant.

\section{Results}

We identified 297,100 diabetes-diagnosed patients, 120,326 men (40.5\%) and 176,774 women (59.5\%); average age and standard deviations were $62.3 \pm$ 12.9 years $(62.3 \pm 13.0$ for men and $62.3 \pm 12.7$ for women); $24.2 \%$ came from the Northern Delegation, $42.9 \%$ from the Southern Delegation, $7.7 \%$ from the Eastern Delegation, $6.1 \%$ from the Western Delegation and 19.1 \% from Nuevo León (Table 1); 87,102 (29.3\%) had at least one diabetes complication, $75,689(25.4 \%)$ of them one microvascular complication and 19,239 (6.4\%) one macrovascular complication. In addition, 13,678 (4.6\%) had some comorbidity and 94,505 (31.8\%) had at least one complication or one comorbidity.

Foot disease was recorded in 50,635 (17.0\%) patients, chronic kidney disease (CKD) in 21,605 (7.2\%), and retinopathy in 13,115 (4.4\%). Ischemic heart disease (IHD) was found in 1,097 (0.37\%), cerebrovascular disease (CVD) in 2,850 (0.9\%) and heart failure in $16,028(5.3 \%)$. Neoplasms within the previous five years were found in 6,456 (2.1\%), anemia in 6,186 (2.0\%) and chronic liver disease in $1,538(0.5 \%)$. In addition, hypoglycemia was recorded in 1,402 (0.4\%). Statistically significant differences were observed in the prevalence of complications in the different geographical regions: any complication (34.9\%) and microvascular complications (32\%) were more prevalent in the Northern Delegation, which is a rather industrial area; macrovascular complications in the Eastern Delegation (12.3\%), which is actually rather rural, and comorbidities in the Southern Delegation (5\%), which is more residential (Table 1).

Average age of patients with microvascular complications was $64.8 \pm 11.9$ years for diabetic foot, $67.9 \pm 11.4$ for chronic kidney disease and $64.9 \pm 11.2$ 


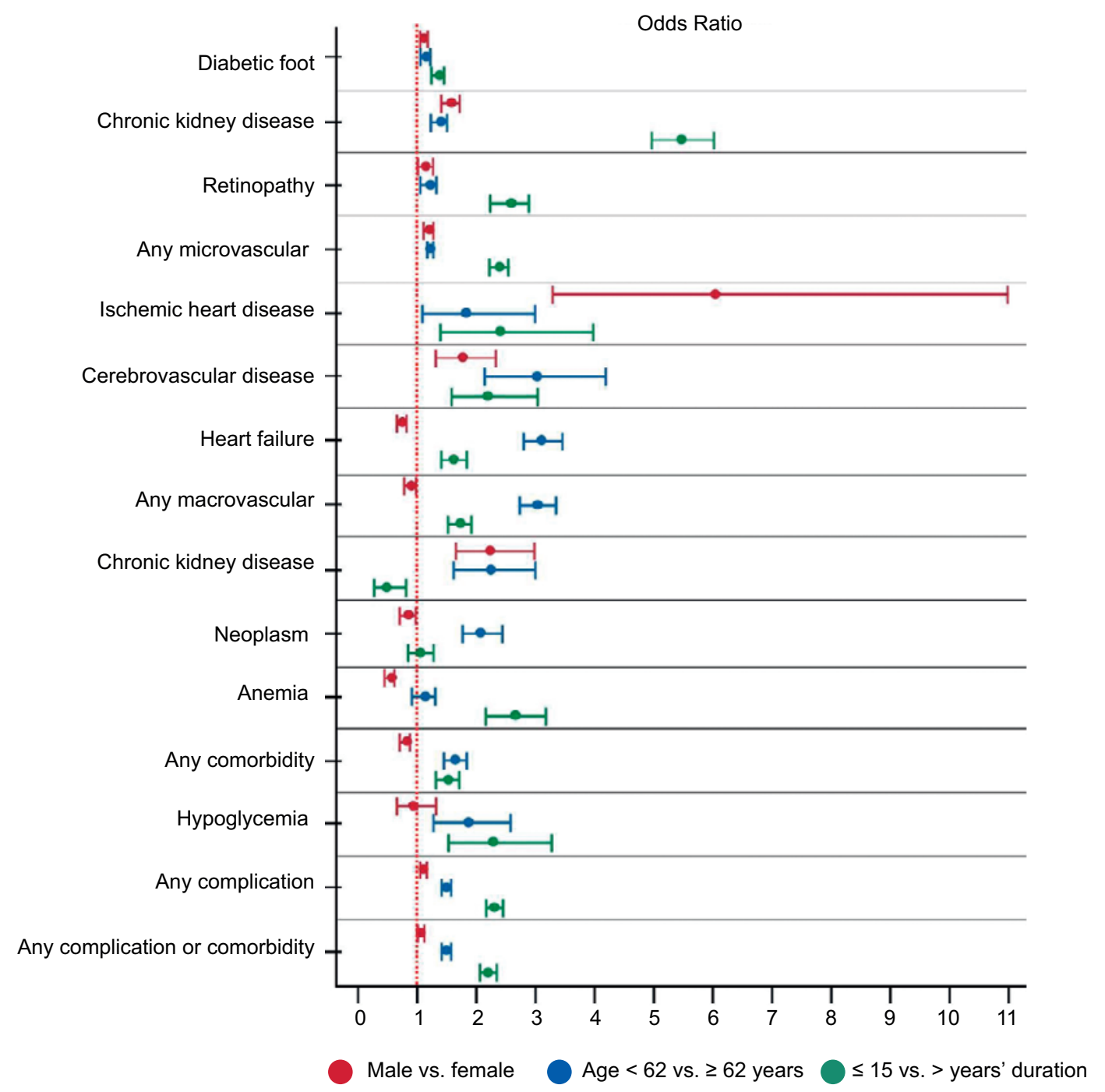

Figure 1. Logistic regression analysis for diabetes complications and comorbidities by gender, age and diabetes duration. Gender was more clearly significant for ischemic heart disease, older age for cardiovascular disease in general and longer diabetes duration for chronic kidney disease.

for diabetic retinopathy. For macrovascular complications, it was $69.3 \pm 10.6,70.9 \pm 10.5$ and $69.7 \pm$ 10.8 years, respectively, for ischemic heart disease, cerebrovascular disease and heart failure. For comorbidities, ages were $67.9 \pm 11.5,66.1 \pm 13.3$ and 65.3 \pm 10.2 years for neoplasms, anemia and chronic liver disease. Diabetes complications were more common in men (any complication $30.2 \%$ ), and comorbidities in women $(4.9 \%)$, although heart failure was more common in women (5.6\%). All complications and comorbidities were more common in subjects $\geq 62$ years of age.

Only in 40,526 cases (13.6\%) was disease duration indicated and in 5,765 (14.2\%) of them, duration was $\geq 15$ years. In this subgroup, all complications were more frequent in individuals with $>15$ years' duration. Only in individuals with chronic liver disease diabetes duration was $<15$ years, but the difference was not statistically significant.

In the logistic regression analysis, the differences by delegation, age, gender and diabetes duration remained constant. The difference by gender was more evident for ischemic heart disease, older age in cardiovascular disease in general and longer duration of diabetes for chronic kidney disease (Figure 1).

There were marked prevalence differences between delegations. Figure 2 shows the ORs with their corresponding $95 \%$ Cls.

A single microvascular complication was recorded in $64,903(21.8 \%)$, two complications in 9,017 (3.0\%) 
Odds Ratio

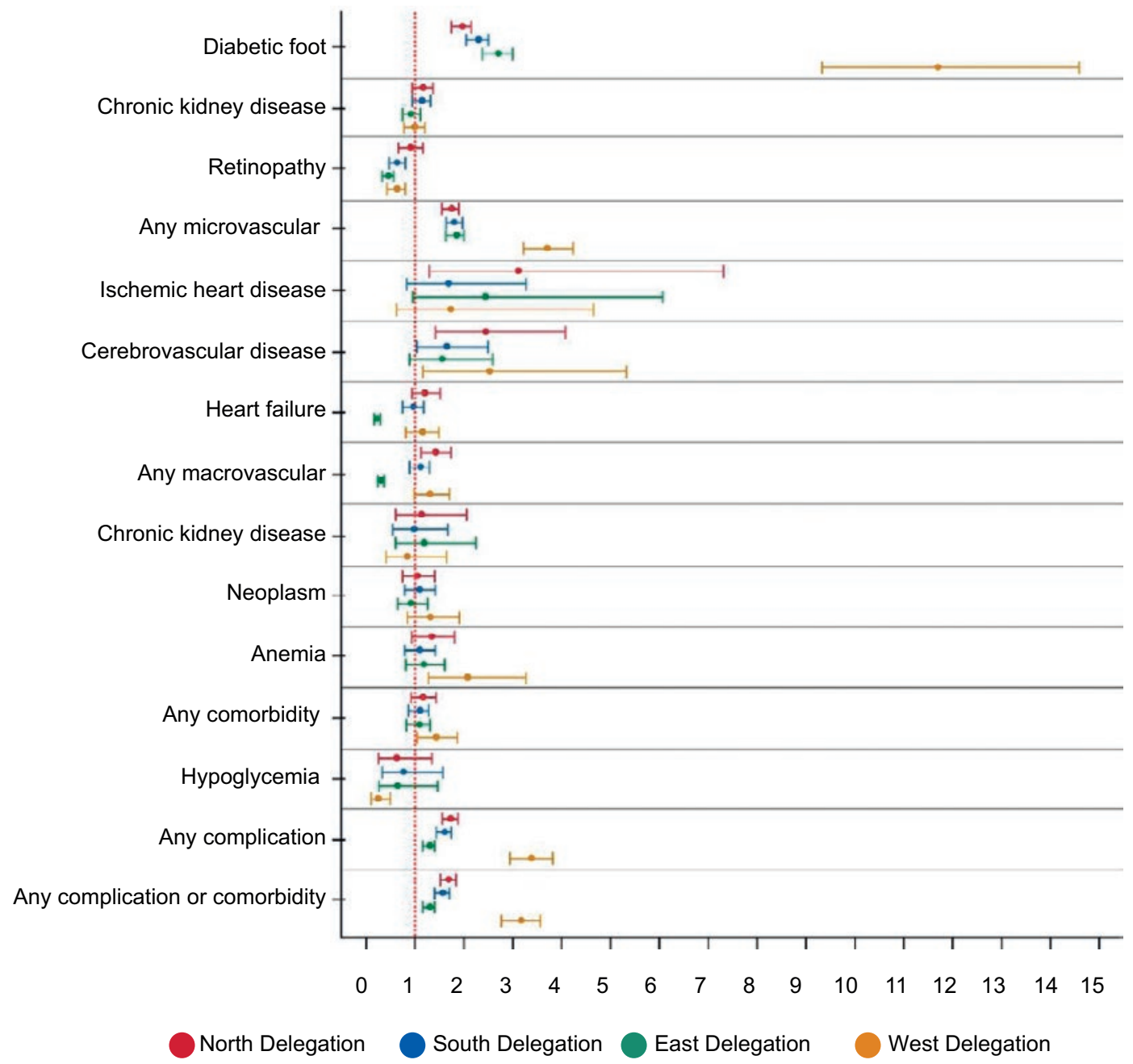

Figure 2. Logistic regression analysis for diabetes complications and comorbidities by Delegation. Important differences were noted by geographic region, especially for diabetic foot.

and three in $806(0.2 \%)$. CKD complications with diabetic foot, retinopathy with diabetic foot or retinopathy with CKD were observed in 4,495 (1.5\%), $2,675(0.9 \%)$ and $1,847(0.6 \%)$ cases, respectively.

A single macrovascular complication was observed in 18,461 cases $(6.2 \%)$, two in $753(0.3 \%)$ and three in $25(0.008 \%)$. Combinations of cerebrovascular disease with heart failure, ischemic heart disease with heart failure or ischemic heart disease with cerebrovascular disease were observed in $392(0.1 \%)$, $299(0.1 \%)$ and $46(0.01 \%)$ cases, respectively.

The presence of any diabetes complication increases the risk of having the others. With the exception of ischemic heart disease, all complications and comorbidities were associated with higher rates of hypoglycemia, with the highest risk being for CKD (OR, 4.4
[3.9-4.9], $p<0.001])$ and the lowest for diabetic foot (OR, 1.6 [1.5 - 1.9], $p<0.001]$ ). Liver cirrhosis was significantly associated with diabetic foot, CKD and heart failure, but not with retinopathy, ischemic heart disease, or cerebrovascular disease (Table 2).

\section{Discussion}

This study indicates diabetes chronic complications just as diagnosed by IMSS family doctors, which are similar to those reported in other countries, with the exception of microvascular complications, which appear to be more common than those reported in Europe..$^{14}$ This contrasts with previous observations indicating that diabetes complications were more common in Mexicans. ${ }^{6}$ Nearly one third of the subjects 
Table 2. Associations between complications and comorbidities in diabetic patients

\begin{tabular}{|c|c|c|c|c|c|c|c|c|c|c|}
\hline Complication & Hypoglycemia & DF & CKD & DR & IHD & CVD & HF & CLD & $\mathbf{N}$ & A \\
\hline Diabetic foot & $\begin{array}{c}1.6 \\
(1.5-1.9)^{\star}\end{array}$ & & & & & & & & & \\
\hline Chronic kidney disease & $\begin{array}{c}4.4 \\
(3.9-4.9)^{*}\end{array}$ & $\begin{array}{c}1.6 \\
(1.5-1.7)^{\star}\end{array}$ & & & & & & & & \\
\hline Retinopathy & $\begin{array}{c}2.6 \\
(2.2-3.0)^{*}\end{array}$ & $\begin{array}{c}1.8 \\
(1.7-1.8)^{*}\end{array}$ & $\begin{array}{c}3.5 \\
(3.3-3.7)^{\star}\end{array}$ & & & & & & & \\
\hline Ischemic heart disease & $\begin{array}{c}0.4 \\
(0.09-1.5) \\
0.161\end{array}$ & $\begin{array}{c}1.2 \\
(1.07-1.4) \\
0.003\end{array}$ & $\begin{array}{c}2.8 \\
(2.4-3.3)^{\star}\end{array}$ & $\begin{array}{c}2.1 \\
(1.7-2.6)^{*}\end{array}$ & & & & & & \\
\hline $\begin{array}{l}\text { Cerebrovascular } \\
\text { disease }\end{array}$ & $\begin{array}{c}2.9 \\
(2.1-4.1)^{*}\end{array}$ & $\begin{array}{c}1.7 \\
(1.5-1.8)^{\star}\end{array}$ & $\begin{array}{c}2.3 \\
(2.1-2.6)^{\star}\end{array}$ & $\begin{array}{c}1.5 \\
(1.3-1.8)^{*}\end{array}$ & $\begin{array}{c}4.5 \\
(3.4-6.1)^{*}\end{array}$ & & & & & \\
\hline Heart failure & $\begin{array}{c}1.7 \\
(1.4-2.1)^{*}\end{array}$ & $\begin{array}{c}1.6 \\
(1.6-1.72)^{*}\end{array}$ & $\begin{array}{c}2.9 \\
(2.8-3.1)^{\star}\end{array}$ & $\begin{array}{c}1.7 \\
(1.6-1.8)^{*}\end{array}$ & $\begin{array}{c}6.7 \\
(5.8-7.6)^{*}\end{array}$ & $\begin{array}{c}2.8 \\
(2.5-3.1)^{*}\end{array}$ & & & & \\
\hline Chronic liver disease & $\begin{array}{c}2.5 \\
(1.6-4.0)^{*}\end{array}$ & $\begin{array}{c}1.3 \\
(1.2-1.5)^{\star}\end{array}$ & $\begin{array}{c}1.9 \\
(1.7-2.3)^{\star}\end{array}$ & $\begin{array}{c}1.1 \\
(0.9-1.4) \\
0.317\end{array}$ & $\begin{array}{c}1.6 \\
(0.8-3.0) \\
0.162\end{array}$ & $\begin{array}{c}1.0 \\
(0.6-1.7) \\
0.948\end{array}$ & $\begin{array}{c}1.5 \\
(1.2-1.8)^{\star}\end{array}$ & & & \\
\hline Neoplasm & $\begin{array}{c}1.4 \\
(1.08-1.9) \\
0.013\end{array}$ & $\begin{array}{c}1.2 \\
(1.18-1.3)^{*}\end{array}$ & $\begin{array}{c}1.5 \\
(1.4-1.6)^{\star}\end{array}$ & $\begin{array}{c}1.2 \\
(1.05-1.3) \\
0.004\end{array}$ & $\begin{array}{c}1.7 \\
(1.3-2.4)^{*}\end{array}$ & $\begin{array}{c}1.2 \\
(0.9-1.5) \\
0.118\end{array}$ & $\begin{array}{c}1.4 \\
(1.3-1.6)^{\star}\end{array}$ & $\begin{array}{c}2.0 \\
(1.6-2.6)^{\star}\end{array}$ & & \\
\hline Anemia & $\begin{array}{c}3.6 \\
(2.9-4.4)^{*}\end{array}$ & $\begin{array}{c}1.6 \\
(1.5-1.7)^{\star}\end{array}$ & $\begin{array}{c}7.3 \\
(6.9-7.8)^{\star}\end{array}$ & $\begin{array}{c}2.1 \\
(1.9-2.4)^{*}\end{array}$ & $\begin{array}{c}2.0 \\
(1.5-2.7)^{*}\end{array}$ & $\begin{array}{c}1.8 \\
(1.4-2.2)^{*}\end{array}$ & $\begin{array}{c}2.0 \\
(1.8-2.2)^{\star}\end{array}$ & $\begin{array}{c}5.3 \\
(4.5-6.3)^{\star}\end{array}$ & $\begin{array}{c}2.2 \\
(2.0-2.5)^{*}\end{array}$ & \\
\hline Any microvascular & $\begin{array}{c}2.7 \\
(2.4-3.0)^{\star}\end{array}$ & N/A & N/A & $\mathrm{N} / \mathrm{A}$ & $\begin{array}{c}1.9 \\
(1.7-2.2)^{*}\end{array}$ & $\begin{array}{c}1.9 \\
(1.8-2.1)^{*}\end{array}$ & $\begin{array}{c}2.09 \\
(2.0-2.1)^{\star}\end{array}$ & $\begin{array}{c}1.5 \\
(1.3-1.7)^{\star}\end{array}$ & $\begin{array}{c}1.3 \\
(1.2-1.4)^{\star}\end{array}$ & $\begin{array}{c}3.4 \\
(3.3-3.6)^{*}\end{array}$ \\
\hline Any macrovascular & $\begin{array}{c}1.9 \\
(1.6-2.3)^{\star}\end{array}$ & $\begin{array}{c}1.6 \\
(1.6-1.7)^{\star \star}\end{array}$ & $\begin{array}{c}2.9 \\
(2.8-3.0)^{\star}\end{array}$ & $\begin{array}{c}1.7 \\
(1.6-1.8)^{*}\end{array}$ & 0 & 0 & 0 & $\begin{array}{c}1.4 \\
(1.2-1.7)^{\star}\end{array}$ & $\begin{array}{c}1.4 \\
(1.3-1.5)^{\star}\end{array}$ & $\begin{array}{c}2.0 \\
(1.8-2.1)^{\star}\end{array}$ \\
\hline Any complication & $\begin{array}{c}2.8 \\
(2.5-3.1)^{\star}\end{array}$ & N/A & $\mathrm{N} / \mathrm{A}$ & $\mathrm{N} / \mathrm{A}$ & $\mathrm{N} / \mathrm{A}$ & N/A & $\mathrm{N} / \mathrm{A}$ & $\begin{array}{c}1.5 \\
(1.4-1.7)^{\star}\end{array}$ & $\begin{array}{c}1.35 \\
(1.3-1.4)^{\star}\end{array}$ & $\begin{array}{c}3.3 \\
(3.1-3.5)^{\star}\end{array}$ \\
\hline Any comorbidity & $\begin{array}{c}2.5 \\
(2.1-3.0)^{*}\end{array}$ & $\begin{array}{c}1.45 \\
(1.4-1.5)^{\star}\end{array}$ & $\begin{array}{c}3.8 \\
(3.6-3.9)^{*}\end{array}$ & $\begin{array}{c}1.6 \\
(1.5-1.7)^{\star}\end{array}$ & $\begin{array}{c}1.9 \\
(1.5-2.3)^{*}\end{array}$ & $\begin{array}{c}1.5 \\
(1.3-1.7)^{\star}\end{array}$ & $\begin{array}{c}1.7 \\
(1.6-1.8)^{\star}\end{array}$ & $\mathrm{N} / \mathrm{A}$ & $N / A$ & $N / A$ \\
\hline $\begin{array}{l}\text { Any complication or } \\
\text { comorbidity }\end{array}$ & $\begin{array}{c}2.8 \\
(2.6-3.2)^{\star}\end{array}$ & $\mathrm{N} / \mathrm{A}$ & $\mathrm{N} / \mathrm{A}$ & $\mathrm{N} / \mathrm{A}$ & $\mathrm{N} / \mathrm{A}$ & $\mathrm{N} / \mathrm{A}$ & $\mathrm{N} / \mathrm{A}$ & $N / A$ & $\mathrm{~N} / \mathrm{A}$ & $\mathrm{N} / \mathrm{A}$ \\
\hline
\end{tabular}

in this study had one chronic diabetes complication (29.3\%) and, additionally, $4.6 \%$ had another diagnosed comorbidity. Strategies implemented by the institution had been previously reported to have reduced the number of preventable hospitalizations associated with diabetes chronic complications. ${ }^{15}$ This might explain the differences in the prevalence of chronic complications between $2006^{6}$ and the present. A recent report indicated that the prevalence of chronic complications that cause permanent disability have increased at the IMSS, with the exception of cardiovascular complications. Such difference might be explained by the fact that we analyzed the complications that occurred in this entire population, whereas that study evaluated the percentage of complications that were observed among patients applying for a disability pension. ${ }^{16}$ However, as pointed out by Arredondo et al., chronic kidney disease, retinopathy, cardiovascular disease, diabetic neuropathy and peripheral vascular disease have a rather high impact on the cost of medical care in Mexico. ${ }^{17}$

Microvascular complications were the most frequently recorded (25.4\%), perhaps because they are diagnosed and treated by the family doctor. Diabetic foot was the most common microvascular complication with a prevalence of $17 \%$, which is higher than that previously reported. ${ }^{6}$ This difference might be related to the difficulty to classify diabetic foot in the 
ICD-10 system, because there is no specific code for this disorder..$^{18}$ Amputations have grown steadily in Mexicans with diabetes, with a current rate of 111 (major) and 162 (minor) per 100,000, respectively. ${ }^{19}$ Geography has an influence on the prevalence of diabetic foot: Mexico City Northern Delegation is a mountainous area where socioeconomic conditions could determine that people do not have access to properly-fitting footwear, while in the Southern Delegation, which is more suburban and has a population of higher socioeconomic status, people might have more capacity to pay for foot care. According to Morbach et al., ${ }^{20}$ this might explain the difference in the prevalence of diabetic foot between both these delegations.

Chronic kidney disease was found in $7.7 \%$ of patients, with geographical differences being significant, but small. It was lower in Nuevo León and, in general, a little lower than that previously reported for Mexico, ${ }^{3}$ much lower than in the United Kingdom ${ }^{21}$ and similar to that of Spain. ${ }^{9}$ This difference might be explained because different evaluation and screening methods are used. In family medicine units, CKD is diagnosed through proteinuria and elevated serum creatinine levels; creatinine clearance measurements are not usually performed and the measurement of microalbuminuria is not available at this level of care.

The prevalence of diabetic retinopathy was $4.4 \%$, with regional differences also being observed. This prevalence is lower than that previously reported for Mexico, which ranges from 22 to $35 \% .{ }^{22}$ The figures in our study are similar to those reported in Spain, ${ }^{9}$ but lower than those reported in Australia, and similar to those previously reported for Mexico $(27.2 \%) .^{13}$ Again, we think that the difference lies in the assessment methods, since when specific strategies to detect retinopathy are applied, prevalence can increase five times $(36 \%)$. $^{23}$

Ischemic heart disease was reported only in $0.3 \%$ of medical records, probably because most forms of IHD are treated in hospitals and not at primary care. In a previous study, $13 \%$ of patients in Mexico City were found to have some form of IHD. ${ }^{24}$ Sabag et al., in the north of the country, reported a prevalence of $10 \%,{ }^{6}$ similar to that reported in other countries. ${ }^{10,25}$ Both older age and diabetes duration were associated with higher prevalence, as previously reported. ${ }^{26}$ In addition, there were regional differences, with the highest prevalence (including $12.3 \%$ of heart failure) being reported in the Eastern Mexico Delegation, which is rural, and, surprisingly, it was lower in Nuevo
León (4.3\%). The rate of cardiovascular diseases has decreased in Mexico ${ }^{27}$ and worldwide, including those for patients with diabetes, but we believe that the difference in rates is due to particularities in diagnostic reporting in our health system and that, in this case, self-report could be more accurate than the medical record. ${ }^{28}$

Diabetes is an indisputable risk factor for cerebrovascular disease, and the prevalence we found $(0.9 \%)$ is lower than that reported in other studies; possibly for the same reasons as those discussed for ischemic heart disease. The fact that this prevalence is 3 -fold higher than that found for IHD is possibly because CVD sequelae are more easily recognizable in the office than those of IHD. Heart failure was diagnosed in $5.3 \%$ of cases and this prevalence is similar to that reported in Spain (4.3\%); ${ }^{9}$ this is a chronic condition that is most likely diagnosed at the family doctor's office. In this group of patients, a higher prevalence of cardiovascular disease is expected, but it may not have been found because of reporting practices in electronic medical records. The family physician needs to know this previous history information in order to introduce or continue secondary prevention strategies. ${ }^{29}$

We also studied comorbidities that, in spite of not being directly related to hyperglycemia, contribute to diabetes morbidity and mortality. Older age and gender, but not disease duration or geographic region, were associated with a higher prevalence of cancer..$^{30}$ In our data, cancer prevalence was associated with all complications and comorbidities, except for cerebrovascular disease.

Anemia is a common finding in patients with diabetes, especially in those with chronic kidney disease. In our patients, the prevalence of anemia seems to be lower than previously reported, even considering that these are not hospital-treated cases. Beyond anemia clinical consequences, a lower than normal total hemoglobin value affects $\mathrm{HbA1c}$ measurements, which represents the goal in these patients for glycemic control. ${ }^{31}$

Liver cirrhosis prognosis worsens in the presence of diabetes, and the presence of cirrhosis in diabetes requires treatment adjustments and limits hypoglycemic drugs options. ${ }^{32}$ We found a prevalence of cirrhosis of $0.5 \%$. Most subjects with cirrhosis had previous liver injuries, as it became evident in the log-linear regression analysis, which showed that prevalence is associated with the male gender and older age, but with a shorter duration of diabetes, as also observed by Anstee et al. ${ }^{33}$ 
Hypoglycemia is important because it reduces the likelihood of reaching glycemic control goals, affects the quality of life and can cause serious harm. It is difficult to compare the hypoglycemia rates because different methods and different diagnostic criteria are often used, especially when cross-sectional and prospective studies are compared. The $0.5 \%$ prevalence that we found appears to be relatively low in comparison with other figures reported in the world. ${ }^{34}$ We believe that this might be due to under-reporting. Serious cases are treated in hospitals and not in the primary care setting. However, the rate we observed increases with age, diabetes longer duration and all chronic complications, with the exception of ischemic heart disease and other comorbidities, but not with patient gender.

It should be noted that Mexico City and the State of Nuevo Leon are among the regions of the country that have reported the highest prevalence of diabetes, and despite the heterogeneity we found, might not be representative of the nation-wide prevalence of chronic complications, which indicates one weakness of the study. These complications are related to the level of disease control (proportion of patients reaching $\mathrm{HbA1c}$, LDL-cholesterol and blood pressure therapeutic goals) and, in Mexico, the proportion of patients reaching these goals is estimated to be small, ${ }^{35}$ and thus we expected a higher proportion of complications. Studies that actively look for complications in a prospective way usually find a difference six times greater in these prevalences. ${ }^{8-12}$ The lack of information on the proportion of patients who achieve therapeutic goals should also be regarded as a limitation of the study. Another limitation is related to the fact that prevalence data were obtained by reviewing medical records, as pointed out in a previous study. ${ }^{36}$ It should be noted that the assignment of ICD-10 codes is made by the doctor who grants medical appointment, depending on the reasons he or she believes motivated the visit, which is quite limited in time and it is possible that not all complications or comorbidities of the patient are recorded. In addition, since complications are recorded in ICD-10 codes, it is impossible to subdivide them into clinical stages or subgroups. Medical care at the IMSS is segmented by levels and regionalized, and some complications are looked after in places (e.g. hospitals) other than where primary care is offered, and thus this could also explain why some of them were not found in the patient record, because the family doctor does not have access to hospital records. When the patient is discharged from the hospital, he/she must deliver a report prepared by the specialist for the family doctor; however, we are not sure whether the family doctor captures the report data in his/her own record. This is a weakness of the IMSS registration system itself.

In general, the prevalence of chronic complications is similar to that reported in other parts of the world when it is obtained from medical records. However, the distribution of this prevalence was different. We found a higher prevalence of diabetic foot and lower prevalence of atherosclerotic disease and diabetic retinopathy. ${ }^{8-13,14,21,23}$

In conclusion, the prevalence of chronic complications of diabetes at the IMSS showed geographical and gender differences. Older age and longer duration of diabetes were also important factors. It is urgent for strategies to prevent diabetes-associated complications and comorbidities to be reinforced at the IMSS.

\section{Acknowledgements}

To Susan Drier, for proofreading of the document in English; David Gómez Trigos, for the selection of medical records and assistance in analysis; to Ricardo Saldaña and Alba Alemán, for technical and administrative support.

\section{References}

1. Diabetes Atlas Committee. Sexta edición. Bélgica: International Diabetes Federation; 2013.

2. Alegre-Díaz J, Herrington W, López-Cervantes M, Gnatiuc L, Ramírez R, Hill M, et al. Diabetes and cause-specific mortality in Mexico City. N Engl J Med. 2016;375:1961-1971.

3. Gutiérrez JP, Rivera-Dommarco J, Shamah-Levy T, Villalpando-Hernández S, Franco A, Cuevas-Nasu L, et al. Encuesta Nacional de Salud y Nutrición 2012. Resultados Nacionales. México: Instituto Nacional de Salud Pública; 2012.

4. Encuesta Nacional de Salud y Nutrición en Medio Camino. Informe Final de Resultados. México: Instituto Nacional de Salud Pública; 2016.

5. Rojas-Martínez R, Basto-Abreu A, Aguilar-Salinas CA, Zárate-Rojas E, Villalpando S, Barrientos-Gutiérrez T. Prevalencia de diabetes por diagnóstico médico previo en México. Salud Publica Mex. 2018;60:224-232.

6. Sabag-Ruiz E, Alvarez-Félix A, Celiz-Zepeda S, Gómez-Alcalá AV. Complicaciones crónicas en la diabetes mellitus. Prevalencia en una unidad de medicina familiar. Rev Med Inst Mex Seguro Soc. 2006;44:415-421.

7. Ibarra CT, Rocha JJ, Hernández R, Nieves RE, Leyva R. Prevalencia de neuropatía periférica en diabéticos tipo 2 en el primer nivel de atención. Rev Med Chile. 2012;140:1126-1131.

8. Gregg EW, Sorlie P, Paulose-Ram R, Gu Q, Eberhardt MS, Wolz M, et al. Prevalence of lower-extremity disease in the US adult population $\geq 40$ years of age with and without diabetes: $1999-2000$ national health and nutrition examination survey. Diabetes Care. 2004;27:1591-1597.

9. Alonso-Morán E, Orueta JF, Fraile-Esteban JI, Arteagoitia-Axpe JM, Marqués-González ML, Toro-Polanco N, et al. The prevalence of diabetes-related complications and multimorbidity in the population with type 2 diabetes mellitus in the Basque Country. BMC Public Health. 2014; 14:1059.

10. Giorda CB, Avogaro A, Maggini M, Lombardo F, Mannucci E, Turco S, et al. Incidence and risk factors for stroke in type 2 diabetic patients: the DAl study. Stroke. 2007;38:1154-1160.

11. Ziegler D, Rathmann W, Dickhaus T, Meisinger C, Mielck A, KORA Study Group. Prevalence of polyneuropathy in prediabetes and diabetes is associated with abdominal obesity and macroangiopathy. Diabetes Care. 2008;31:464-469. 
12. Wong TY, Mwamburi M, Klein R, Larsen M, Flynn H, Hernández-Medina M, et al. Rates of progression in diabetic retinopathy during different time periods: a systematic and meta-analysis. Diabetes Care. 2009;32:2307-2313.

13. Wong TY, Klein R, Amirul-Islam A, Cotch MF, Couper DJ, Klein BE, et al. Three-year incidence and cumulative prevalence of retinopathy: the atherosclerosis risk in communities study. Am J Opthalmol. 2007;143:970-976.

14. Morgan C, Peters J, Currie C. The changing prevalence of diagnosed diabetes and its associated vascular complications in a large region of the UK. Diabet Med. 2010;27:673-678.

15. Lugo-Palacios DG, Cairns J, Masetto C. Measuring the burden of preventable diabetic hospitalisations in the Mexican Institute of Social Security (IMSS). BMC Health Serv Res. 2016;16:333.

16. Ascencio-Montiel IJ, Kumate-Rodríguez J, Borja-Aburto VH, Fernández-Garate JE, Konik-Comonfort S, Macías-Pérez O, et al. Survival rates and worker compensation expenses in a national cohort of Mexican workers with permanent occupational disability caused by diabetes. BMC Public Health. 2016;16:921.

17. Arredondo A, Azar A, Recamán AL. Diabetes, a global public health challenge with a high epidemiological and economic burden on health systems in Latin America. Glob Public Health. 2018;13:780-787.

18. Mayfield JA, Strand T, Toya A. A call for specific codes for diabetes foot and eye care. Diabetes Care. 1995;18(3):418-421.

19. Cisneros-González N, Ascencio-Montiel IJ, Libreros-Bango VN, Rodríguez-Vázquez H, Campos-Hernández A, Dávila-Torres J, et al. Índice de amputaciones de extremidades inferiores en pacientes con diabetes. Rev Med Inst Mex Seguro Soc. 2016; 54:472-479.

20. Morbach S, Lutale JK, Viswanathan V, Möllenberg J, Ochs HR, Rajashekar S, et al. Regional differences in risk factors and clinical presentation of diabetic foot lesions. Diabet Med. 2004; 21:91-95.

21. Hill CJ, Cardwell C, Patterson C, Maxwell AP, Magee GM, Young RJ, et al. Chronic kidney disease and diabetes in the National Health Service: a cross-sectional survey of the UK National Diabetes Audit. Diabet Med. 2014;31:448-454

22. Asociación Mexicana de Retina, Sociedad Mexicana de Oftalmología, Asociación Panamericana de Oftalmología. Resultados del Día Panamericano de Detección de Retinopatía Diabética (3 de julio de 1999, día "D"). Rev Mex Oftalmol. 2005;79:88-92.

23. Yau J, Rogers S, Kawasaki R, Lamoureux EL, Kowalski JW, Bek T, et al. Global prevalence and major risk factors of diabetic retinopathy. Diabetes Care. 2012;35:556-564.

24. Wacher N, Silva M, Valdez L, Cruz M, Gómez-Diaz R. Causas de descontrol metabólico en atención primaria. Gac Med Mex. 2016;152:350-356.

25. Bragg F, Li L, Smith M, Guo Y, Chen Y, Millwood I, et al.; China Kadoorie Biobank Collaborative Group. Associations of blood glucose and preva- lent diabetes with risk of cardiovascular disease in 500000 adult Chinese: the China Kadoorie Biobank. Diabet Med. 2014;31:540-551.

26. Yeap B, McCaul K, Flicker L, Hankey GJ, Almeida OP, Golledge J, et al. Diabetes, myocardial infarction and stroke are distinct and duration-dependent predictors of subsequent cardiovascular events and all-cause mortality in older men. J Clin Endocrinol Metab. 2015; 100:1038-1047.

27. Borja-Aburto V, González-Anaya J, Dávila-Torres J, Rascón-Pacheco RA González-León M. Evaluation of the impact on non-communicable chronic diseases of a major integrated primary health care program in Mexico. Fam Pract. 2015;33:219-225.

28. Cristina T, Williams J, Parkinson L, Sibbritt DW, Byles JE. Identification of diabetes, heart disease, hypertension and stroke in mid- and older-aged women: comparing self-report and administrative hospital data records. Geriatr Gerontol Int. 2016;16:95-102.

29. Low Wang $C$, Hess $C N$, Hiatt W, Goldfine AB. Clinical update: cardiovascular disease in diabetes mellitus atherosclerotic cardiovascular disease and heart failure in type 2 diabetes mellitus. Mechanisms, management, and clinical considerations. Circulation. 2016:133:2459-2502.

30. Joost $\mathrm{H}$. Diabetes and cancer: epidemiology and potential mechanisms. Diab Vasc Dis Res. 2014;11:390-394.

31. Jones S, Smith D, Nag S, Bilous MT, Winship S, Wood A et al. Prevalence and nature of anaemia in a prospective, population-based sample of people with diabetes: Teesside anaemia in diabetes (TAD) study. Diabet Med. 2010;27:655-659.

32. Elkrief L, Rautou PE, Sarin S, Valla D, Paradis V, Moreau R. Diabetes mellitus in patients with cirrhosis: clinical implications and management. Liver Int. 2016;36:936-948.

33. Anstee QM, Targher G, Day CP. Progression of NAFLD to diabetes mellitus, cardiovascular disease or cirrhosis. Nat Rev Gastroenterol Hepatol. 2013;10(6):330-344.

34. Khunti K, Alsifri S, Aronson R, Cigrovski-Berković M, Enters-Weijnen C Forsén $\mathrm{T}$, et al. Rates and predictors of hypoglycaemia in 27585 people from 24 countries with insulin-treated type 1 and type 2 diabetes: the global HAT study. Diabetes Obes Metab. 2016;18:907-915.

35. Flores-Hernández $\mathrm{S}$, Saturno-Hernández $\mathrm{P}$, Reyes-Morales $\mathrm{H}$, Barrientos-Gutiérrez T, Villalpando S, Hernández-Ávila M. Quality of diabetes care: the challenges of an increasing epidemic in Mexico. Results from two national health surveys (2006 and 2012). PLoS One. 2015;10: e0133958.

36. Wacher NH, Reyes-Sánchez M, Vargas-Sánchez HR, Gamiochipi-Cano M, Rascón-Pacheco RA, Gómez-Díaz RA, et al. Stepwise strategies to successfully recruit diabetes patients in a large research study in Mexican population. Prim Care Diabetes. 2017;11:297-304. 